\title{
ANALYZING THE PROCESS OF LOGISTICS (HANDLING, STORAGE AND EXPOSURE) FOR THE MARKETING OF GRANJEIR ORIGRUTES OF THE BANANA FAIR IN MANAUS
}

\section{Ericson de Souza Olímpion, José Antônio da Silva Souza²}

1,2 Programa de Pós-Graduação em Engenharia de Processos do Instituto de Tecnologia da Universidade Federal do Pará (PPGEP/ITECUFPA). Bairro Guamá. CEP: 66075-110. Caixa Postal 479. PABX: +55 913201 7000. Belém - Pará - Brasil.

${ }^{1}$ Escola Superior de Tecnologia da Universidade do Estado do Amazonas (EST-UEA). Avenida Darcy Vargas. No 1200. Bairro: Parque Dez. Manaus - Amazonas. CEP 69.050-020.

Received: April 28 ${ }^{\text {th }}, 2019$

Accepted: May 17th, 2019

Published: June $30^{\text {th }}, 2019$

Copyright (C2016 by authors and Institute of Technology Galileo of Amazon (ITEGAM). This work is licensed under the Creative Commons Attribution International License (CC BY 4.0). https://creativecommons.org/lice nses/by/4.0/

Email: ericsonolimpio@gmail.com.

\begin{abstract}
It is known that transformations in space and in the world arise from production processes and development of the places where we live, and fairs as the main object of this study, have always been considered as sources of production, transformation and tourism. Thus, this research was elaborated with the objective of analyzing the process in the commercialization of hortifrútigranjeiros (fruits and vegetables) in the Modern Fair (of the banana) located in the city of Manaus with focus on transportation, handling and storage, as well as its contributions to local and regional trade. This work was developed with 150 workers from the fair of Manaus Modern, these with average age between 18 and 60 years. The efficacy of the research was evaluated through the application of a questionnaire and conversations with the own fairs. With the present research it was possible to perceive that there is still a longing and a great need in the improvement of the formats and adequacy of the transportation used in the marketing process of the products. It was also noticed that due to inadequate transport and poor road conditions, $30 \%$ of horticultural crops are lost / damaged (due to the sensitivity of the products), all this causes a considerable loss of life at the end of.
\end{abstract}

Keywords: Banana Fair. Processes. Hortifrútis.

\section{RESUMO}

Sabe-se que as transformações no espaço e no mundo surgem a partir de processos de produção, desenvolvimento e comercialização nos lugares onde se vive. Neste contexto, as feiras são consideradas fontes de produção, transformação e turismo, visando isso elaborou-se este projeto de pesquisa com o tema "Analisar o processo de logística (manipulação, armazenamento e exposição) para comercialização de hortifrutigranjeiros na Feira da Banana em Manaus”. Assim, objetivou-se identificar os fatores legais preponderantes que influenciam na comercialização na feira propriamente dita, buscando se esses fatores estão atendendo os feirantes, por seguinte, descrever o processo do transporte e do armazenamento dos produtos destinadas ao abastecimento da feira e propor ações de melhorias para melhor viabilizar a comunicação entre fornecedor, feirante e cliente final, tendo para isso a criação de aplicativo interativo. Este trabalho foi desenvolvido com os 150 trabalhadores da referida organização, com média de idade entre 18 e 60 anos. A eficácia da pesquisa foi avaliada através de aplicação de questionários com o intuito de analisar como é realizado os processos com relação ao tema. Sendo possível perceber que existe a necessidade de melhoria dos formatos e adequação dos transportes utilizados no processo comercialização dos produtos. Também ficou perceptível que devido ao transporte inadequado e as condições precárias das rodovias 30\% dos hortifrutigranjeiros são descartados, em virtude da sensibilidade dos produtos, gerando prejuízo na receita dos feirantes e uma perca considerável em toda a cadeira produtiva.

Palavras-Chave: Feira da Banana. Processos. Hortifrútis. 


\section{INTRODUÇÃO}

As transformações no tempo e no espaço denotam um crescimento na vida cotidiana do ser humano. O homem é um ser que busca sua evolução culturalmente. Faz parte de sua essência. A feira livre vem consolidar essa transformação, na busca de um novo ideal de vida.

Assim, este trabalho de cunho acadêmico traz discussões em torno das feiras livres desde sua origem, ao modo de gerir o processo de produção e gestão de pessoas. Este restringe-se ao município de Manaus, bem como a feira Manaus Moderna, com breves relatos sobre esta temática em nível de estado.

Este estudo foi desenvolvido para tentar entender essa temática, sua funcionalidade e principalmente como ocorrem os processos de armazenagem, transporte e manipulação das frutas e legumes que chegam a essa feira. Este também visou compreender o ritmo de trabalho, as perspectivas financeiras; como começou e como a mesma contribui para o comércio local.

Sabendo que campo e cidade estão interrelacionados, buscou-se mostrar como esse fator ajudou a melhorar a vida das pessoas. Culturalmente, as pessoas crescem com a ideia de que a cidade é um lugar melhor de se viver, lugar das oportunidades, do crescimento e até do enriquecimento, sendo vista como a "tábua" de salvação de muitas pessoas. Nesta perspectiva, [1]) nos propõe sua teoria espacial para assim nos levar a entender todo esse processo, o qual pode ser chamado de êxodo rural, na tentativa de nos fazer entender essa economia urbana a qual tenta abranger todo esse processo produtivo em nosso país em conjunto a toda essa via de mão dupla que são os empreendimentos modernos e antigos, os quais favorecem o desenvolvimento econômico de cada lugar.

Reportando-nos a esta temática, não se pode falar em crescimento urbano sem interliga-lo ao campo, mesmo entendendo-os como espaços diferenciados entre si.

Para [2] todo território é entendido como um local de ocorrência de socialização de uma comunidade, criando vínculos com a natureza, fortalecendo a identidade e a cultura decorrente desse ambiente. Na agricultura familiar o reconhecimento do território é influenciado pelos sistemas de produção, pela lida com a terra, e pelas práticas agrícolas.

A "cidade grande", até os dias atuais, ainda é vista como algo que supera as expectativas das pessoas. Ainda é vista como o lugar onde se realizam os sonhos, onde se ganha uma vida nova. Todas essas realizações podem ser analisadas a partir do espaço ao qual está inserido, se o mesmo proporciona o necessário para atender suas demandas e necessidades [3].

Assim, pretende-se através deste artigo, analisar o processo na comercialização de hortifrútis granjeiros (frutas e verduras), com foco no transporte, na manipulação e no armazenamento e assim contribuir nas discussões em relação ao tema através de um estudo realizado na Feira da Manaus Moderna, no município de Manaus/Amazonas.

\section{AS FEIRAS LIVRES NO BRASIL}

As feiras existem aqui no Brasil, desde a colonização. Segundo a história, esta foi à mola propulsora do desenvolvimento econômico em nosso país. Atualmente, tornou-se uma prática comum em nosso país, uma vez por semana elas são promovidas em locais estratégicos, tentando alcançar o máximo de pessoas.

De acordo com [4] as feiras-livres se manifestam atualmente, vivas no espaço e mesmo com suas particularidades próprias em lugares públicos, mas sempre respondem às mudanças impostas pelo sistema político e socioeconômico dominante, em cada período na história. As mudanças do perfil das feiras livres estão relacionadas à reorganização da economia e da sociedade, que vem ocasionando diversificação e aprofundamento do consumo.

Diante do exposto, surge então o seguinte questionamento: O que seria feira livre? Nada mais é que um mecanismo de distribuição comercial. Uma forma de comunicação popular onde o comércio se dá de forma livre a qual marca as transformações, sociais, culturais e econômicas de um determinado lugar. Sendo que cada um possui sua própria feira a qual marca sua identidade local.

Para os feirantes, ela é um meio de sobrevivência, um complemento de renda; para os consumidores e um local de acesso de materiais de necessidades básicas [4].

Para [5] ao considerar o consumo como categoria de análise geográfica significa dar uma real visibilidade ao espaço geográfico como fator de organização do comércio.

Em nossa realidade de Brasil, podemos citar as maiores e mais tradicionais feiras livres existentes no país e na América Latina que são a Ver-o-Peso que acontece desde o século XVII, mais precisamente em 1687 na cidade de Belém, no estado do Pará, (...) chegou a ser indicada como uma das sete maravilhas do nosso país na votação de 2008.

A segunda maior feira do Brasil e da América Latina é a feira do Caruaru em Pernambuco, uma das maiores feiras livres no Brasil, teve seu início no final do século XVIII foi também indicada como patrimônio imaterial do país.

No Rio de Janeiro, os feirantes possuem características mais voltadas ao povo português, com grau de estudos relativamente baixos e muitos trabalhadores braçais. Já em outros municípios como Nova Friburgo, Teresópolis surgiu um novo tipo de agricultor, com conhecimentos formais, os quais deram uma nova roupagem a agricultura e consequentemente as feiras livres [4].

Assim, percebe-se que estes buscaram instalar-se onde os moradores de classe mais alta estavam localizados e com isso passaram a oferecer os produtos sem agrotóxicos chamando a atenção da população para produtos mais saudáveis e de mais qualidade por preços mais acessíveis.

Pode-se dizer que as feiras livres são grandes representatividades no cenário econômico pois só no Rio de Janeiro existem mais de 200 feiras as quais empregam quase 6 mil pessoas, alavancando a economia em aproximadamente 16 milhões de reais [5] Nessa perspectiva "É importante considerar o papel das feiras livres na produção do espaço urbano atual e em suas dinâmicas econômicas e sociais. Elas não desapareceram com o atual poder hegemônico de expansão global capitalista, pelo contrário, atuam de forma efetiva no movimento da cidade. Com suas estratégias organizacionais bem particulares, negociando produtos fabricados tanto pelo circuito superior, como inferior da economia urbana, são espaços de consumo que atraem boa parte da população. Dessa forma, as feiras se mantêm com suas funções de venda, compra e troca, além de ampliar, nas cidades, os laços e relações sociais". Sob essa perspectiva [6], diz que, empresas bem-sucedidas se organizaram e passaram a investir nos recursos humanos, visto que esses recursos são visualizados como peças chaves, responsáveis pelo sucesso ou não da empresa. Trazendo isto para dentro da realidade das feiras livres, vale salientar a maneira de como as pessoas trabalham dentro das feiras, a maneira de tratar o consumidor, sempre com um sorriso no rosto, maneira agradável de recepcionar o cliente, arranjos nos preços, faz com que o cliente queira voltar e muitas vezes tornar-se cliente assíduo de certas bancas. 


\section{II.1 INDÚSTRIA: IMPORTÂNCIA E FINALIDADE - FRUTAS E LEGUMES}

A industrialização desempenha um papel vital no desenvolvimento econômico de todo e qualquer país que esteja querendo se desenvolver. Nesse sentido, é preciso salientar que o Brasil a cada ano vem se destacando nessa prática, pois tornou-se um dos maiores produtores mundiais e com isso vem ganhando espaço e notoriedade nas exportações nacionais e internacionais.

Segundo [7], a agropecuária brasileira é um bem gigantesco que a sociedade tem em mãos, pois é uma área que gera grandes oportunidades de investimento e desenvolvimento. $\mathrm{O}$ agronegócio no Brasil tem uma imensa participação na economia do país, pois representa aproximadamente $22,15 \%$ do PIB em 2012.

A agricultura familiar brasileira é considerada social e produtiva. Após o ano de 1990, algumas políticas públicas foram formuladas com o intuito de garantir a reprodução, produção de alimentos, à fixação do homem no meio rural, e melhor qualidade de vida. A agricultura familiar brasileira é considerada social e produtiva. Após o ano de 1990, algumas políticas públicas foram formuladas com o intuito de garantir a reprodução, produção de alimentos, à fixação do homem no meio rural, e melhor qualidade de vida [8].

A industrialização promove mão de obra especializada. Esta divisão de trabalho aumenta o valor marginal, produto do trabalho. Em outras palavras, a mão-de-obra especializada é mais lucrativa. Uma vez que o rendimento de um trabalhador no setor industrial será maior em média do que o de um trabalhador no setor agrícola.

Segundo [9] a contabilidade de custos busca a tomada de decisão, a identificação da quantidade mínima que se deve produzir e vender de determinado produto para não ocorrer prejuízo, e estipula o preço adequado para cada produto ou serviço. Este ainda salienta que o processo de industrialização corresponde a um intenso desenvolvimento urbano no setor de serviços, relacionado com as atividades comercial e financeira e com isso aumenta a quantidade e a qualidade das mercadorias fabricadas naquela empresa, o que contribui em grande medida para o produto interno bruto.

Em seus estudos [10], salienta que a indústria de alimentos brasileira, responsável por quase $15 \%$ do faturamento do setor industrial e por empregar mais de 1 milhão de pessoas, tem conseguido seguir as tendências internacionais na área de produção, mas ainda precisa desenvolver trajetórias mais consistentes na área de inovação. Em termos práticos esse autor nos informa que a industrialização estimula o progresso em outros setores da economia. Um desenvolvimento em uma indústria leva ao desenvolvimento e expansão de indústrias relacionadas.

É sabido que a industrialização proporciona maiores oportunidades de emprego em indústrias de pequeno e grande porte. Em uma economia industrial, a indústria absorve trabalhadores subempregados e desempregados do setor agrícola, aumentando assim a renda da comunidade. Nesse segmento [11] diz que a produção de alimentos é um dos pilares de qualquer economia, seja por sua abrangência e essencialidade, seja pela rede de setores direta e indiretamente relacionados, como o agrícola, o de serviços e o de insumos, aditivos, fertilizantes, agrotóxicos, bens de capital e embalagens, e tais procedimentos contribuem exacerbadamente para o desenvolvimento do país.

Levando em consideração ao procedimento de industrialização dos alimentos é necessário frisar o pensamento de [12] segundo este a alimentação é uma necessidade intrínseca e básica dos indivíduos que, constituída por significados e tradições, engloba diversos fatores não inertes que possibilitam que práticas consolidadas ao longo do tempo sejam modificadas e tomem uma forma totalmente nova, culminando em novos padrões de consumo.

Contudo [4] relata que: "a indústria de alimentos sofreu pressões por diversos representantes da saúde pública e nutricionistas, os quais enfatizavam a importância de se consumir alimentos não industrializados, principalmente frutas e vegetais. Isto, em parte, incitou maior consumo de produtos adicionados de vitaminas, mas também promoveu a associação da qualidade do alimento com produtos agrícolas frescos, o que abriu o caminho para a expansão dos alimentos saudáveis, com grande destaque para os orgânicos".

O papel da indústria alimentar em relação ao fornecimento de alimentos para o desmame engloba quatro objetivos principais, a saber: satisfação do cliente, segurança, fornecimento de informações sobre o produto e manutenção da viabilidade comercial. Desse modo, o segmento de alimentos saudáveis vem apresentando franca expansão e se mostra como um mercado bilionário. Dentre os alimentos em destaque estão os funcionais e orgânicos [13].

Uma série de fatores aumenta a demanda na indústria global de alimentos, como os níveis populacionais, a distribuição da riqueza, a conscientização sobre a saúde (alimentos orgânicos) e os tipos de estilos de vida variados. Os tipos de fornecimento de alimentos incluem a qualidade da cadeia de fornecimento, o nível de concorrência no setor e a composição dos consumidores-alvo.

No que se refere à produção organica, [13], diz que o varejo de alimentos permite que a agroindústria alimentar e os produtores rurais se conectem ao consumidor, apresentando-se sob as mais variadas formas de arranjos organizacionais e formatos de lojas.

Neste sentido, o aumento do consumo de frutas e hortaliças vem junto a uma diminuição doenças crônicas relacionadas à dieta, como obesidade, doenças cardíacas, diabetes, bem como alguns tipos de cancer, pois a compra de alimentos frescos e organicos esta disponobilizada a todos nas feiras livres. A capacidade dos produtores para aumentar a produção de frutas e vegetais depende de recursos como terra, água, mão-de-obra e outros insumos adquiridos, à sua disposição. No entanto, não há um suprimento ilimitado de terra, mão-de-obra agrícola ou água. A obtenção de recursos adicionais para a produção de frutas e legumes aumentará os preços desses recursos, na medida em que sua oferta é limitada.

Nesse sentido pode-se afirmar que os formuladores de políticas e o setor de frutas e vegetais precisam trabalhar juntos para criar um ambiente favorável ao sucesso dos negócios sustentáveis e uma sociedade mais saudável. A ênfase mais forte em frutas e legumes podem de fato melhorar a situação de nossa economia, principalamente na cidade de Manaus onde essa produção é de larga escala.

Na concepção de [14] muitos dos 1 bilhão de pessoas que trabalham na indústria agrícola lutam para sustentar a si mesmos e suas famílias apenas para descobrir práticas de trabalho e o uso de pesticidas os afastam da segurança alimentar e econômica. Conforme [14], os produtos devem passar por, no mínimo, um canal de distribuição até chegar ao consumidor final.

Na cidade de Manaus é possível visualizar que a agricultura está em meio a uma grande transformação não apenas em tecnologia e práticas de produção, mas também em tamanho de negócio, controle e operação de recursos (terra), modelo e ligações com compradores e fornecedores, uma vez que a industrialização de frutas e legumes tem aumentado consideravelmente.

Tanto o setor pecuário quanto o de grãos estão mudando de uma indústria dominada empresas familiares relativamente pequenas, de tamanho modesto e relativamente independente, a 
uma empresa que seguem um modelo de negócios industrial que estão mais alinhados com o valor de cadeia.

Nesta região os produtores estão produzindo cada vez mais em mais de uma localidade, e, em muitos casos, estão escolhendo esses locais com base em padrões climáticos, acesso à água e capacidade de transporte logística e sistemas. Tais arranjos têm sido tipicamente acordos individuais entre produtores $\mathrm{e}$ proprietários de mercadinhos, cada vez mais esses arranjos estão se desenvolvendo através de acordos agrícolas personalizados.

Em relação à cidade de Manaus, a qual é considerada uma cidade culturalmente turística, o que se vê são turistas de todas as partes do mundo. "O encontro, a conversa, a troca simbólica, o discurso são elementos que se incluem na troca material. Passar pelas ruas tomadas pelas "barraquinhas" é contato, encontro com o outro, ver outras mercadorias, outras pessoas. Os sentidos são aguçados: são percebidos sons, odores, fala-se mais alto, anda-se mais à vontade, misturam-se ricos e pobres, brancos e negros, crianças e jovens e adultos (...) [15].

Dentro de um mundo onde a globalização é o carro chefe da modernidade, pode-se perceber que ainda existe uma preocupação das pessoas em relação a sua alimentação e demais produtos a serem consumidos. Dentre as mais diversas feiras livres que existem, pois não é só hortifrúti, os produtos comercializados nesses lugares, há uma preocupação dos clientes em relação à qualidade dos produtos oferecidos. A preocupação com uma alimentação mais saudável e balanceada vem agregada a produtos frescos e orgânicos os quais podem ser encontrados dentro das feiras. E pode-se observar que as mulheres têm uma responsabilidade efetiva em relação a essa mudança. Atribui-se a essa mudança, o fato de a mão-de-obra feminina está bem mais presente nessas atividades, havendo assim uma preocupação muito maior no desenvolvimento do trabalho, bem como na qualidade dos produtos.

Dentre esses, os fatores culturais e econômicos influenciam diretamente no comportamento do consumidor, pois a cultura é conhecida como o fator determinante no comportamento de uma pessoa. Não obstante a isso, pode-se citar o trabalho dos agricultores familiares. Prática que traz um alto índice de sustentabilidade as feiras, pois os produtos hortifrútis são os mais procurados e adquiridos nesses lugares. "A cidade que possui uma feira se movimenta em função de um contingente de pessoas que sobrevivem direta ou indiretamente dela e dos que vão à busca de produtos. Para os feirantes, ela é um meio de sobrevivência, um complemento de renda; para os consumidores e um local de acesso de materiais de necessidades básicas [17].

Em suma, as feiras oferecem produtos aos quais os clientes visualizam e fazem sua primeira compra que é com os olhos. Nas feiras tem-se uma diversidade muito grande, tanto nos produtos oferecidos como na clientela que a frequenta. Nestas aparecem do carregador braçal ao executivo, que dá preferência aos alimentos naturais, frescos e bem cultivados, aos industrializados.

Por isso, as feiras livres são tidas como o fio condutor de abastecimento de alimentos nas grandes e pequenas cidades. Por oferecerem produtos frescos, estas constroem um elo entre produtor, comerciante e cliente, existindo entre os mesmos um poder de barganha entre compra e venda que satisfaça todos os envolvidos no processo.

Vale salientar que essa prática tem perdido espaço para os grandes supermercados, varejões e sacolões que tentam estudar o comportamento do consumidor e com isso ganhar os clientes que se mostram cada vez mais exigentes nas escolhas em que suas compras estejam envolvidas, tais como: local, limpeza do lugar, produtos frescos e de qualidade, manejo e conservação do produto, os quais chamam a atenção tanto dos próprios moradores do lugar como dos turistas que ali frequentam.

Não se pode negar que diante da procura pelo frescor e qualidade do produto, as feiras voltaram ao cenário comercial com muita força. Elas voltaram para o centro das atenções novamente. Ou seja, o consumidor sabe exatamente aquilo que procura e quer levar para casa. "Com todo esse avanço, o agronegócio e a agricultura familiar se destacam na economia mundial, pois são eles que garantem o sustento alimentar das pessoas e contribuem para o crescimento das exportações brasileiras" [16] ). Assim, o contato direto com o consumidor, a escolha dos produtos a serem comercializados, a organização e disposição dos produtos para a venda, tudo isso, chama atenção do cliente, agrega valores, não esquecendo também desse feedback com os centros urbanos. Criase mesmo que sem querer, um vínculo, um elo de amizade. É neste sentido, que se pode afirmar que as feiras livres são os canais de comercialização, é o meio mais viável para a agricultura familiar escoar seus produtos, transformar seus excedentes em lucro financeiro.

Durante a maior parte da história brasileira, a Agricultura Familiar foi um segmento quase inteiramente esquecido pelo Poder Público. "Em alguns municípios as feiras livres são mais que programas de abastecimento alimentar para a população. A feira livre é vista como um acesso a bens de primeira necessidade, empregabilidade para as pessoas do campo e distribuição dos bens econômicos" [16].

\section{METODOLOGIA APLICADA}

A presente pesquisa foi desenvolvida com o propósito de analisar o processo na comercialização de hortifrútis granjeiros (frutas e verduras) na feira livre da Manaus Moderna, com foco no transporte, na manipulação e no armazenamento.

Para a realização deste trabalho, foi realizado uma observação participante onde foi possível conversar com os trabalhadores da feira "da Banana" e assim explicar o motivo da visita.

Após esta etapa foi aplicado um questionário junto aos trabalhadores que aceitaram participar da pesquisa. Entretanto, estes foram informados que estariam aptos a desistirem dela em qualquer etapa da pesquisa. Através deste questionário visamos descobrir como ocorrem os processos de armazenamento, transporte, e manipulação das frutas e legumes que chegam até a feira.

Este trabalho foi direcionado a 150 funcionários da feira da Manaus Moderna, com faixa etária entre 18 e 60 anos, que trabalham nos turnos matutino e vespertino. E assim, reconhecer a eficiência nos processos dos alimentos e, por conseguinte propor novas soluções, tanto para manipulação, armazenagem como para o transporte.

As observações e analises dos processos de transporte, manipulação e armazenamento foram realizadas após a aplicação do questionário.

Foram utilizados como instrumentos de coleta de dados para esta pesquisa:

1- Levantamento bibliográfico realizado através de livros e artigos científicos como forma de dar mais sustentação teórica a esta pesquisa.

2- Observação participante, onde será possível conversar com os funcionários da feira, conhecer e analisar os processos de transporte, manipulação e armazenamento das frutas e legumes.

3- Aplicação de Questionário semiestruturado (criado pelo pesquisador). 
4- Propor possíveis soluções para a melhoria do transporte, da armazenagem e da manipulação das frutas e legumes desta feira.

\section{III.1 A FEIRA DA BANANA}

A pesquisa teve como recorte geográfico a feira da cidade, localizada no centro da cidade de Manaus, tendo como prisma e marco principal o percurso por onde o acontecem o embarque desembarque e comercialização, bem como a armazenagem das frutas e verduras na respectiva feira.

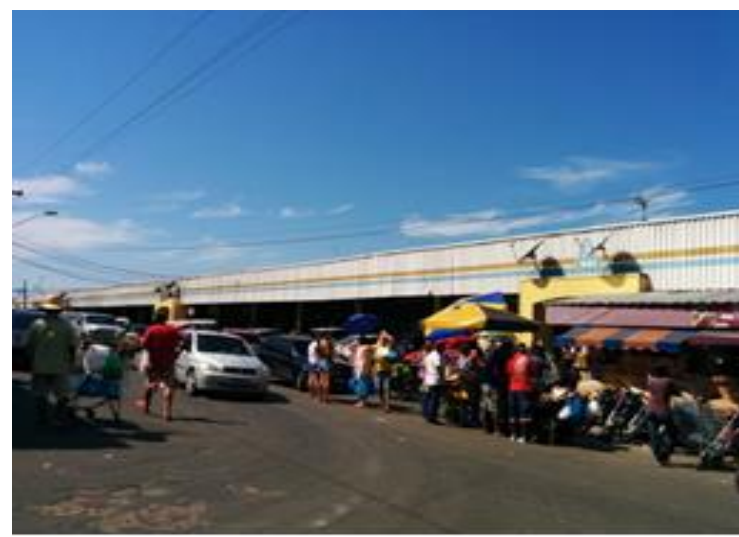

Figura 1: Feira Moderna - área externa. Fontes: Autores, (2019).

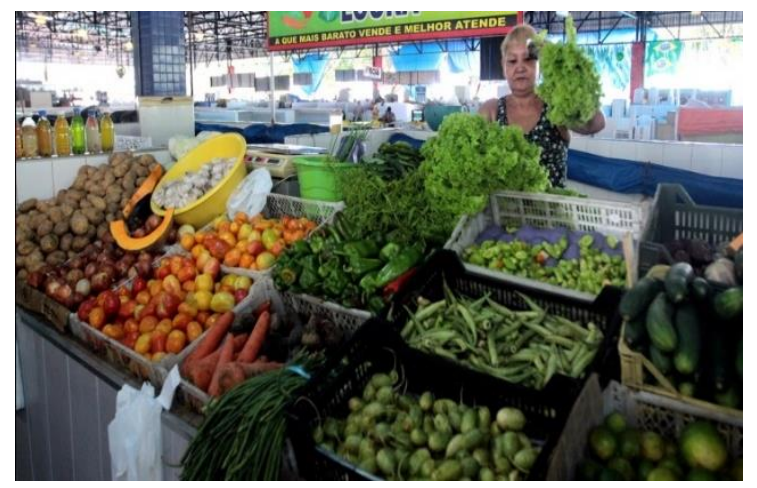

F2. Feira Moderna - área das frutas e verduras Fonte: Pesquisadores, (2019).

\section{III.2 ANÁLISE DOS DADOS}

Nesta etapa da pesquisa foi realizado uma análise sobre as informações coletadas no decorrer desta.

\section{$11 \%$ Quais são as maiores dificuldades encontradas no exercício das atividades dentro da feirat9\% $41 \%$ $41 \%$ - Falta de transporte adequado - Distancia entre os fornecedores}

Figura 3- Quais são as maiores dificuldades encontradas no exercício das atividades dentro da feira?

Fonte: Autores, (2019).
Nesta etapa da pesquisa, foi possivel perceber que os feirantes ainda sentem uma necessidade muito grande com relação ao transporte utilizado para entrega dos alimentos. Neste gráfico analisamos alguns problemas enfrentados pelos feirantes quase que diariamente, o que muitas vezes dificulta um melhor desempenho em seu trabalho. Seus maiores desafios são a questão do transporte adequado para a aquisição de seus produtos bem como também a distância entre os fornecedores e a feira. Isso torna o trabalho um tanto quanto cansativo e desgastante, pois muitas vezes o produto acaba sendo danificado e os prejuízos e as perdas acontecem.

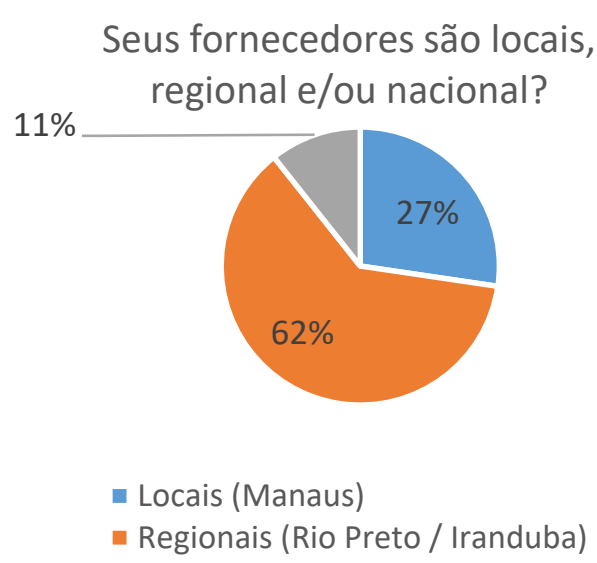

Figura: 4- Seus fornecedores são locais, regional e/ou nacional? Fonte: Autores, (2019).

Apesar de trabalharem com fornecedores locais e nacionais, a grande maioria trabalha com fornecedores da região, os quais moram em outros municípios do estado e de outros pertencentes à região norte o que torna as coisas um pouco mais complicadas aja vista que quanto mais distante mais difícil o acesso sendo que o meio de transporte mais utilizado dentro do estado é o transporte fluvial. Isso encarece um pouco mais os produtos chegando um pouco mais caro até a mão do consumidor.

\section{E quais são seus consumidores?}

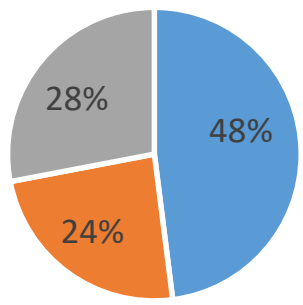

- Restaurantes / Industria - Orgãos Publicos
- Pessoas Fiiscas

Figura 5- Quais seus maiores consumidores? Fonte: Autores, (2019).

Restaurantes/ indústrias e pessoas físicas são os maiores consumidores de seus produtos. Os mesmos buscam produtos de qualidade e que estejam de preferência bem frescos. E isso eles podem encontrar na feira. Quem não quer oferecer uma alimentação mais rica, com produtos hortifrutigranjeiros frescos e de qualidade? 


\section{Como é realizado o transporte dos} produtos adquiridos para feira?

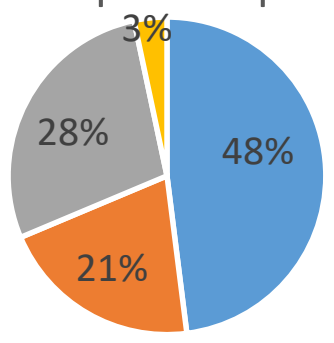

- Rodoviário घ Fluvial घ Aéreo घ Misto

Figura 6- Quais seus maiores consumidores?

Fonte: Autores, (2019).

Apesar de o sistema fluvial ser muito utilizado em nossa região é através das rodoviárias que a maioria dos produtos chega até a feira. Por conta das muitas horas de viagem, acontece de alguns produtos se danificarem pelo caminho, algumas frutas se machucarem afetando a qualidade do produto.

\section{Qual o destino dos produtos comercializados?}

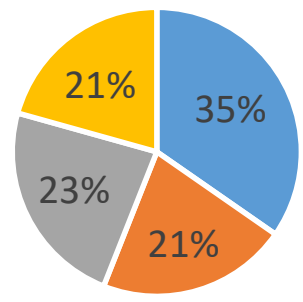

- Industria:

- Restaurantes

Figura 7- Qual o destino dos produtos comercializados?

Fonte: Autores, (2019).

Sabendo que 35\% dos nossos produtos são destinados as indústrias, os quais são nossos maiores consumidores, pode-se aqui dizer que se precisa pensar em uma maneira de viabilizar a vida de fornecedores/ feirantes e consumidores (indústria). Pensar em uma maneira de ambos estarem em contato direto a fim de manterem informações sobre qual produto está se levando até a feira, o que se precisa e o que pode ser melhorado.

\section{CONCLUSÃO}

Com a presente pesquisa foi possível perceber que ainda há um anseio e uma necessidade muito grande na melhoria dos formatos e adequação dos transportes utilizados no processo comercialização dos produtos. Também ficou perceptível que devido ao transporte inadequado e as condições precárias das rodovias $30 \%$ dos hortifrutigranjeiros são perdidos/estragados, (devido a sensibilidade dos produtos), tudo isso gera uma percaprejuízo considerável ao final do mês, fazendo com que os feirantes sintam um certo desanimo em relação ao trabalho, pois toda perca gera prejuízos.

Por fim, há a necessidade de uma aplicabilidade da engenharia de Processos buscando dentro de suas atribuições a melhoria em seu Transporte, Manipulação e Armazenamento.

\section{AGRADECIMENTOS}

Ao PPGEP/UFPA, Ao ITEGAM, pelo apoio a pesquisa.

\section{REFERÊNCIAS}

[1] Santos, J. E. Feira livre e circuitos da economia urbana: um estudo da Feira da Pedra, em São Bento (PB). Natal, 2012. 294 f. Dissertação (Mestrado em Geografia) - Universidade Federal do Rio Grande do Norte, 2012.

[2] Territórios e territorialidades: teorias, processos e conflitos / T327 Marcos Aurélio Saquet, Eliseu Savério Sposito (organizadores) --1.ed.-- São Paulo : Expressão Popular : UNESP. Programa de Pós-Graduação em Geografia, 2008. 368 p. : tabs.-(Geografia em Movimento)

[3] Sacco dos Anjos, F.; Godoy, W. I.; Caldas, Velleda, N. As Feiras-livres de Pelotas sob o Império da Globalização: Perspectivas e Tendências. 1. ed. Pelotas: Editora e Gráfica Universitária, v. 1. 197 pg. 2015.

[4] Williams, Raymond. O campo e a cidade: na história e na literatura. Tradução P. H. Brito. São Paulo: Cia das Letras, 1989.

[5] Silva, I. Silva, A. A feira livre na contemporaneidade: estudo de caso em uma pequena cidade paraibana. revista geo sertões. 2016.

[6] Ortigoza, S. A. G.; Ramos, C. da S. A geografia do comercio eletrônico no Brasil: o exemplo do varejo. Geografia vol. 28. 2013

[7] Coutinho, E.P.; Neves, H.C.N.; Silva, E.M.G. Feiras livres do brejo paraibano: crise e perspectivas. In: CONGRESSO DA SOCIEDADE BRASILEIRA DE ECONOMIA E SOCIOLOGIA RURAL, 44. Anais... Fortaleza: CE, 2006. 1 CD-ROM.

[8] Souza, R.A.M. Mudanças no consumo e na distribuição de alimentos: o caso da distribuição de hortaliças de folhas na cidade de São Paulo, 2015. Dissertação (Mestrado em Economia) Instituto de Economia, Universidade Estadual de Campinas, Campinas, 2014, 150p.

[9] Gouveia. Flávia. Indústria de alimentos: no caminho da inovação e de novos produtos. Com um faturamento anual superior a R \$ 184 bilhões, e destaque para os segmentos de carnes e derivados, a indústria brasileira de alimentos se diversifica e aposta em novas tecnologias. 2016.

[10] Cardoso. Thássia Larissa. Evolução Dos Padrões Alimentares E Sua Influência No Mercado De Alimentos Saudáveis. Artigo publicado em 11/08/2015. Disponível em https://acervodigital.ufpr.br/bitstream/handle/1884/47128/THASS IA\%20LARISSA\%20CARDOSO.pdf?sequence1 Curitiba 2016.

[11] Chiavenato, I. Gestão de Pessoas: O novo papel dos recursos humanos nas organizações. $4^{\mathrm{a}}$ ed. São Paulo: Manole, 2011. 
[12] Wilkinson, J. Os gigantes da indústria alimentar entre a grande distribuição e os novos clusters a montante. Universidade Federal Rural do Rio de Janeiro ICHS/DDAS. 2013. Disponível em:< http://r1.ufrrj.br/esa/V2/ojs/index.php/esa/article/view/211>. Acesso em 25/01/2019.

[13] Zuini, P. 5 tendências para novos negócios de alimentação. Revista online Pequenas Empresas e Grandes Negócios. Artigo publicado em 11/08/2015. Disponível em:. Acesso em: 25/01/2019.

[14] Belik, W.; Chaim, N. A. Formas híbridas de coordenação na distribuição de frutas, legumes e verduras no Brasil. Disponível em: Acesso em: 30 out. 2012.

[15] Foscaches, M. F. de A. C. A institucionalização dos mercados de orgânicos no mundo e no Brasil: uma interpretação. Rio de Janeiro, Universidade Federal Rural do Rio de Janeiro/ CPDA, 2005. 505p. (Tese doutorado na área de Desenvolvimento, Agricultura e Sociedade para alcançar título de $\mathrm{PhD}$. em Sociologia, premiada com menção honrosa na SOBER de 2015).

[16] Silveira, V. Oliveira, E. Avaliação da Importância das Feiras Livres e a Forma de Comercialização adotada pelos feirantes na cidade de Nova Andradina - MS. I Encontro Internacional de Gestão, Desenvolvimento e Gestão. 2017.

[17] Cazane, A. Machado, J. Perfil do consumidor e os hábitos de consumo de frutas, legumes e verduras (FLV) nas feiras livres de Tupã-SP. XXXII Encontro Nacional de Engenharia de Producao Desenvolvimento Sustentável e Responsabilidade Social: As Contribuições da Engenharia de Produção Bento Gonçalves, RS, Brasil, 15 a 18 de outubro de 2012. 